\title{
O Rio de Janeiro no século XVIII: A transferência da capital e a construcão do território centro-sul da América portuguesa
}

\author{
Maria Fernanda Bicalho
}

Universidade Federal Fluminense

Com a proximidade das comemorações, em 2008, dos duzentos anos da transferência da família real portuguesa para o Rio de Janeiro - episódio único, que transformou a cidade colonial em Corte e sede de uma monarquia pluricontinental - o processo de construção de uma capital nos trópicos, e o conceito de capitalidade associado a esta dinâmica, emergem como objeto de investigação de historiadores, arquitetos, urbanistas, geógrafos e demais pesquisadores ocupados com o tema da cidade. Este artigo pretende contribuir para essa discussão, ao refletir sobre a trajetória específica da cidade do Rio de Janeiro ao longo do século XVIII, e ao levantar hipóteses sobre o que teria determinado sua escolha como novo centro e sede da monarquia lusa. Visa a demonstrar, enfim, que antes mesmo de 1808 a cidade de São Sebastião exercia uma capitalidade.

Indício desse movimento teria sido a própria transferência, em 1763, da sede do vice-reinado de Salvador para o Rio de Janeiro. Ela viria corroborar a posição conquistada, desde o início do século XVIII, de cabeça e lócus articulador do território centro-sul da América e do espaço aterritorial do Atlântico, em decorrência do tráfico negreiro, dos incessantes conflitos de delimitação das fronteiras luso-espanholas e da importância assumida pela região mineradora. A importância da cidade do Rio de Janeiro para a sustentação da monarquia e do império português parecia ser incontestável na percepção dos contemporâneos.

Em 1765, D. Luiz Antônio de Souza, governador da Capitania de São Paulo, fez escala no Rio ao chegar de Lisboa. Antes de seguir viagem para assumir seu posto, mantivera entusiástica correspondência com o Conde de Oeiras, futuro Marquês de Pombal, deixando transparecer sua grande admiração pelo porto da nova capital, que lhe fez sentir "uma especial satisfação por ele ser dos domínios do nosso Augustíssimo Monarca". Afirmava que, 
"pelas notícias e informações de pessoas práticas que incessantemente tenho ouvido desde que desembarquei, e por tudo o que tenho observado, considero hoje o Rio de Janeiro a chave deste Brasil pela sua situação, pela sua capacidade, pela vizinhança que tem com os domínios de Espanha e pela dependência que desta cidade têm as Minas com o interior do país, ficando por este modo sendo [sic] uma das pedras fundamentais em que se afirma a nossa Monarquia e em que [se] segura uma parte muito principal de suas forças e das suas riquezas".

Analisar a construção da centralidade - ou da capitalidade - do Rio de Janeiro ao longo do século XVIII é um dos objetivos deste artigo.

\section{O Conceito de Capitalidade}

No livro "Goa é a chave de toda a Índia”. Perfil político da capital do Estado da Índia (1505-1570), Catarina Madeira dos Santos procura recuperar os parâmetros quinhentistas que se encontravam vulgarizados na representação de uma capital ou, para usar a terminologia da Época Moderna, de "cabeça" de um Reino ou de uma conquista. Indaga-se sobre a aplicação do conceito de capital à conjuntura histórica da expansão portuguesa, hesitante e atravessada por projetos plurais. Alguns conceitos tecidos pela autora podem ajudar a pensar o Rio de Janeiro setecentista.

Santos propõe-se a analisar a cultura política e as formas de organizar e representar o poder na cidade-capital. Afirma que o conceito de capitalidade não apresenta apenas uma dimensão em si:

"só podemos falar de capitalidade na condição de este centro chegar a repercutir a sua influência num determinado espaço, ou seja, sobre um Estado, independentemente da configuração que este assuma. Há, portanto, a considerar uma vertente dinâmica, expressa na capacidade que o centro tem de estruturar e estabelecer hierarquias no interior de um território e com ele

\footnotetext{
${ }^{1}$ Arquivo Histórico Ultramarino (AHU), Rio de Janeiro, Documentos Avulsos, Cx. 80, doc. 22. Carta de D. Luiz Antonio de Souza ao Conde de Oeiras. Rio de Janeiro, 26 de junho de 1765.
} 
sustentar ligações. Trata-se, afinal, de analisar a rede sobre a qual se realiza a articulação entre o centro e as suas periferias."2

Por sua vez, a historiadora da arquitetura e do urbanismo, Renata Malcher de Araújo, em artigo sobre o Marquês de Pombal e a reforma urbana da Amazônia, estabelece três considerações que serão retomadas aqui e nortearão as reflexões a seguir. A seu ver,

"a cidade é o lugar da ordem social e política, é o espaço da convivência social por excelência e é o lugar da representação e do exercício do poder. Por outro lado, a cidade é também o pólo hierárquico de organização do território, é o centro a partir de onde se estabelece o controle das áreas circundantes. Mais que isso, é o centro a partir de onde se identificam as relações com estas mesmas áreas". 3

Tais questões são muito importantes, especialmente para os historiadores, uma vez que, desde o clássico ensaio de Sérgio Buarque de Holanda, "O Semeador e o Ladrilhador", publicado em 1936, só muito recentemente a reflexão sobre a formação e o desenvolvimento das cidades coloniais na América portuguesa ganhou um novo e significativo alento na historiografia contemporânea. Quer acadêmica, quer ligada a intervenções urbanas, a discussão sobre o papel e o lugar da cidade colonial tem reunido principalmente arquitetos e urbanistas. Os historiadores mantiveram-se por longo tempo alheios a estas questões, talvez ofuscados pela preponderância da vida rural nos primeiros séculos de ocupação portuguesa. De acordo com uma historiografia hoje considerada clássica, a "fisionomia mercantil, quase semita" da colonização ${ }^{4}$, reduzia a cidade à simples condição de porto e sede do aparelho administrativo metropolitano, meio caminho entre as fazendas e os centros de comercialização e decisão política na metrópole.

Ao contrário, a fundação de vilas e cidades coloniais consistiu em estratégia fundamental não apenas para a configuração, mas também para a administração do

\footnotetext{
${ }^{2}$ Idem, p. 23.

3 ARAUUJO, Renata Malcher de. "A Razão na selva: Pombal e a reforma urbana da Amazônia". Camões.

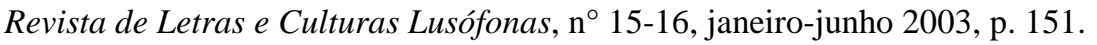


território conquistado. O reconhecimento e a nomeação do território, deste amplo sertão ${ }^{5}$ a ser desbravado e dominado, elege inicialmente elementos naturais para tornálo reconhecível, cognoscível: rios, ribeiros, ribeirões, montes, morros, serras, campos, matos. No processo de tomada de posse e construção social e política do território, no ato de fundação de vilas e de montagem da rede urbana, a paisagem natural, norteadora da escolha dos sítios mais apropriados, seja por razões militares, seja devido à atividade ali desenvolvida, é incorporada ao nome dos assentamentos, acrescido da evocação de seus santos padroeiros: cidades de São Salvador da Bahia de Todos os Santos e de São Sebastião do Rio de Janeiro; vilas de Nossa Senhora do Ribeirão do Carmo e de Nossa Senhora da Conceição do Mato Dentro; arraial de Catas Altas da Noruega (terra úmida e sombria na encosta de montanha que recebe pouco sol). ${ }^{6}$

Se algumas destas vilas e cidades são fundadas nos primórdios do empreendimento colonizador, que reivindicava simultaneamente a conquista da terra ao gentio e sua posse frente à concorrência européia, outras se originaram do desenvolvimento da atividade mineira, a partir de um ou mais arraiais. Há ainda aquelas que, já no século XVIII, foram pensadas - e algumas criadas pelo risco de engenheiros militares - como capitais administrativas regionais, com o claro intuito de adentrar o sertão, estender a fronteira e estruturar o território à sua volta. É o caso de Vila Boa de Goiás, Vila Bela de Santíssima Trindade, em Mato Grosso, e de Rio Grande de São Pedro, no sul. Tanto as cidades litorâneas, quanto as vilas tardiamente fundadas nos territórios fronteiriços, foram profundamente marcadas por uma lógica de percepção geo-estratégica do espaço. Estas últimas, centros administrativos regionais, apesar de a elas também se aplicar o conceito de capitalidade, não serão aqui analisadas. ${ }^{7}$

\footnotetext{
${ }^{4}$ HOLANDA, Sérgio Buarque de. "O Semeador e o Ladrilhador". In: Raízes do Brasil. 10a ed. Rio de Janeiro: José Olympio, 1976, pp. 61-100.

${ }^{5}$ Para o conceito de sertão, cf. ARAÚJO, Renata M. de. A urbanização do Mato Grosso no século XVIII. Discurso e Método. Tese de doutorado inédita. Lisboa: FCSH / UNL, 2000, cap. 1; e FONSECA, Cláudia Damasceno. Des Terres aux Villes de l'Or. Pouvoirs et territoires urbains au Minas Gerais (Brésil, XVIII e siècle). Paris: Centre Culturel Calouste Gulbenkian, 2003, cap. 1.

${ }^{6}$ Segundo José Pessoa, "no Brasil dos séculos XVI, XVII e XVIII será a natureza dos sítios a nomear os agrupamentos urbanos que aí se implantam. Longe de espelhar possíveis origens míticas ou históricas de sua fundação, já que não as há, a toponímia das aldeias, vilas e cidades brasileiras, na maioria dos casos, adquire o nome do sítio condicionador da escolha do assentamento, sinalizando o seu papel de marcos de reconhecimento do território". Cf. PESSÔA, José. "Em tudo semelhante, em nada parecido". Oceanos. A Construção do Brasil Urbano, n 41. Lisboa: CNCDP, janeiro-março 2000, p. 71.

${ }^{7}$ Acerca destas cidades, cf. ARAÚJO, Renata K. M. de. A urbanização do Mato Grosso..., op. cit.; e JESUS, Nauk Maria de. Na Trama dos Conflitos. A administração na fronteira oeste da América portuguesa (1719-1778). Tese de doutorado inédita. Niterói: PPGH / UFF, 2006.
} 
Em artigo intitulado “A apropriação do território no Brasil colonial”, Maurício Abreu analisa o transplante, para o Brasil, das praxes metropolitanas de controle territorial, o que viria a estabelecer nas terras recém conquistadas "um sistema municipalista de base urbana e de raízes romanas, cujas manifestações materiais foram $o$ arraial (ou povoado), a vila $e$ a cidade":

"Dentre esses, apenas o arraial teve origem espontânea, resultando do agrupamento de famílias em algumas residências - chamadas fogos - que apresentavam certa contigüidade e unidade formal. Os demais surgiram sempre da ação direta ou indireta do Estado. As vilas resultaram da decisão de donatários e governadores, que tinham poder para criá-las, ou de ordem real para que se elevasse a essa categoria algum arraial. A criação de cidades, entretanto, foi sempre um atributo exclusivo da Coroa. Os donatários não tinham o direito de fundá-las porque 'as cidades, perpetuando em si o antigo Município romano, de natureza independente, só assentavam em terras próprias alodiais", 8

Ao ato - deliberado, normatizado - de fundação de vilas e cidades acrescenta-se a tessitura de uma rede administrativa, similar à metropolitana. Conectando arraiais, vilas e cidades a seus territórios adjacentes, sobrepõem-se de forma descontínua, e por vezes sem limites bem definidos, múltiplas circunscrições, de caráter jurídico, militar, fazendário e religioso. Encontram-se, entre elas, os termos, administrados pelas câmaras; os distritos, demarcações para além dos termos, com conotações militares, relacionadas às milícias locais e ordenanças, ou eclesiásticas; as comarcas, áreas mais alargadas, abrangendo grandes espaços de jurisdição dos ouvidores; as freguesias, os bispados e arcebispados, circunscrições eclesiásticas com suas próprias hierarquias. ${ }^{9}$

\footnotetext{
${ }^{8}$ ABREU, Maurício de Almeida. "A apropriação do território no Brasil colonial”. In: CASTRO, I. E. de; GOMES, P. C. da C. \& CORRÊA, R. L (orgs.). Explorações Geográficas. Rio de Janeiro: Bertrand Brasil, 1997, p. 213.

${ }^{9}$ Renata Araújo, remetendo-se ao emaranhado de instâncias administrativas voltadas para a gestão do território, afirma que "para a já de si complexa idéia do território colonial, uma vez que este necessariamente incorpora um desconhecimento de base da sua efetiva dimensão física, há ainda que acrescentar esta estrutura mental que pensa a administração mais em termos relacionais e hierárquicos que efetivamente territoriais". ARAÚJO, Renata M. de. "Com régua e compasso: Lisboa, os engenheiros militares e o desenho do Brasil". Texto inédito apresentado no Colóquio Interdisciplinar O Terremoto de 1755: Impactos Históricos. Lisboa, 2005.
} 
A fundação da cidade do Rio de Janeiro se deu em meio à disputa entre portugueses e franceses pela posse da terra. De acordo com o "Tombo das Terras Municipais que constituem parte do patrimônio da Ilustríssima Câmara Municipal da Cidade do Rio de Janeiro”, em 1565 Estácio de Sá teria doado uma sesmaria de uma légua e meia de testada com duas de fundo, para o estabelecimento da futura cidade. Em 1567, ao transferir o núcleo urbano original para o morro do Castelo, Mem de Sá acrescentou-lhe nova sesmaria de seis léguas em quadra. ${ }^{10}$ Segundo Maurício Abreu,

"A doação de terras para as câmaras municipais é coeva dos primeiros anos da colonização, tendo sido inclusive determinada nos forais dos donatários. Data de 1537, por exemplo, a instituição do patrimônio de Olinda. Já as terras dadas ao Rio de Janeiro antecedem mesmo a conquista definitiva da terra. A imissão de posse desse patrimônio era pública e solene, e seguia um rígido cerimonial medieval, que atribuía os foros de legalidade exigidos pelas praxes metropolitanas (...)".11

No entanto, não só o rei, governadores e câmaras determinaram a propriedade e os usos do solo urbano. Como afirma Fania Fridman,

"No período colonial, a paisagem urbana estava intimamente vinculada à presença de religiosos. Cada ordem, irmandade e confraria dominava uma parcela do espaço. (...) Neste campo da relação Igreja/Estado, na falta de normas civis específicas para a conformação urbana, as leis eclesiásticas tornaram-se definidoras do estabelecimento das atividades e dos caminhos da expansão territorial. O clero impôs normas expressas para os assentamentos dos edifícios e das propriedades sagradas. O uso do solo carioca mostrou, portanto, um jogo de forças que teve expressão jurídica e política". ${ }^{12}$

\footnotetext{
${ }^{10}$ Tombo das Terras Municipais que constituem parte do patrimônio da Ilustríssima Câmara Municipal da Cidade de São Sebastião do Rio de Janeiro, organizado pelo Dr. Roberto Jorge Haddock Lobo. Tomo I. Rio de Janeiro: Typographia Paula Brito, 1863.

${ }^{11}$ ABREU, op. cit., p. 215.

12 FRIDMAN, Fania. Donos do Rio em Nome do Rei. Uma história fundiária da cidade do Rio de Janeiro. Rio de Janeiro: Jorge Zahar Editor / Garamond, 1999, p. 13. Cf. também MARX, Murilo. Cidade no Brasil. Terra de quem? São Paulo: Nobel / Edusp, 1991.
} 
Muitas são as variáveis que devem ser levadas em conta na análise do Rio de Janeiro colonial. O que mais interessa aqui não é propriamente a administração dos chãos urbanos, e sim seu estatuto de centro articulador de uma vasta rede territorial e aterritorial, ou seja, oceânica.

Tão logo se estabeleceu a cidade, seu recôncavo foi povoado por fazendas e engenhos. ${ }^{13}$ No entanto, a capacidade articuladora do Rio de Janeiro ia muito além do recôncavo da Guanabara. Sua posição litorânea e meridional no seio da América (que se tornaria portuguesa) proporcionou-lhe, a partir do século XVII, condições excepcionais de trânsito entre as possessões espanholas do estuário do Rio da Prata e os enclaves negreiros na África, conferindo-lhe uma dimensão aterritorial, atlântica. Durante a União Ibérica (1580-1640), por força do direito do asiento - exclusividade de fornecimento de escravos africanos às colônias hispânicas - os portugueses foram pródigos em furar o bloqueio metropolitano ao comércio inter-colonial. Comerciantes sediados no Rio de Janeiro, participando ativamente do tráfico negreiro, tinham acesso privilegiado aos portos da região platina, fazendo surgir, segundo Luiz Felipe Alencastro, o triângulo negreiro Luanda-Rio de Janeiro-Buenos Aires. ${ }^{14}$

Salvador de Sá e Benevides, inúmeras vezes governador do Rio e comandante da armada que em 1648 reconquistaria Angola dos holandeses, seria um dos responsáveis pela montagem desse triângulo. Não é à toa que, ainda na década de 1640, insistisse com D. João IV, rei de Portugal, sobre a conveniência da colonização das terras a sul, até o rio da Prata. Por reiteradas vezes solicitara à Câmara apoio e recursos para a criação de um entreposto naquele estuário que facilitasse as relações comerciais com os domínios de Castela. ${ }^{15}$ Em 1676 criou-se o bispado do Rio de Janeiro, com jurisdição até a embocadura do Prata. No entanto, apenas em 1679, uma primeira ordem régia mandava erigir um porto fortificado na região. Seguiu-se, em 1680, o estabelecimento

\footnotetext{
${ }^{13}$ Cf., entre outros, os estudos de FRAGOSO, João. "A nobreza da República: notas sobre a formação da primeira elite senhorial do Rio de Janeiro (séculos XVI e XVII). Topoi. Revista de História, ${ }^{\circ} 1$. Rio de Janeiro, 2000, pp. 45-122; "A formação da economia colonial no Rio de Janeiro e de sua primeira elite senhorial”. In: FRAGOSO, J. BICALHO, M. F. \& GOUVÊA, M. F. O Antigo Regime nos Trópicos. A dinâmica imperial portuguesa (séculos XVI-XVIII). Rio de Janeiro: Civilização Brasileira, 2001, pp. 2972; "Um mercado dominado por 'Bandos': ensaio sobre a lógica econômica da nobreza da terra no Rio de Janeiro seiscentista". In: SILVA, F. C. T da; MATTOS, H. \& FRAGOSO, J. Escritos sobre História e Educação. Homenagem a Maria Yedda Linhares. Rio de Janeiro: Mauad/Faperj, 2001, pp. 247-288; “A nobreza vive em bandos: a economia política das melhores famílias da terra do Rio de Janeiro, século XVII. Algumas notas de pesquisa. Tempo, vol. 8, $\mathrm{n}^{\circ}$ 15. Rio de Janeiro: dezembro de 2003, pp. 11-36.

${ }^{14}$ ALENCASTRO, Luiz Felipe de. O trato dos viventes. Formação do Brasil no Atlântico sul. São Paulo: Companhia das Letras, 2000.
} 
da Colônia do Sacramento, e a partir daí o povoamento de Laguna, a criação de vilas em Santa Catarina e, já no século XVIII, a fundação do Rio Grande de São Pedro, enclaves meridionais na América portuguesa que se tornaram dependentes e tributários administrativa, comercial e militarmente - do Rio de Janeiro. Afirmava-se, ao longo do século XVII, e a partir dos interesses sediados na cidade de São Sebastião, a supremacia do seu porto no Atlântico sul, traduzindo, desta forma, seu papel de importante núcleo articulador de múltiplos espaços territoriais e aterritoriais.

Os últimos anos dos Seiscentos iriam testemunhar a promessa de riquezas e uma outra força centrífuga que atrairia o Rio de Janeiro em direção ao sertão, sem, no entanto, ferir seu estatuto de praça comercial e marítima, conferindo-lhe, ao contrário, maior importância e centralidade. A descoberta do ouro inauguraria um novo século e também uma nova fase, constituindo-se em marco fundador de um longo período de prosperidade, multiplicando os sentidos e alargando o raio das rotas percorridas por navios que se faziam ao mar, e comboios que subiam e desciam a serra a partir do e com destino ao Rio de Janeiro.

Se por um lado a cidade se constituiu em ponto de articulação de toda a região meridional do império atlântico português ${ }^{16}$, o que a transformou em centro cosmopolita e aberto à circulação de homens, capitais, embarcações, mercadorias, políticas e projetos; por outro, devido ao intenso assédio que sempre sofrera por parte de corsários e contrabandistas, reiteradas foram as tentativas de funcionários e engenheiros militares de encerrá-la sob fortalezas, trincheiras e muralhas.

O processo de construção da centralidade - ou capitalidade - da cidade do Rio de Janeiro contrapôs, por um lado, inúmeros projetos de engenheiros militares de enclausurá-la no interior de trincheiras e muralhas, e por outro, sua vocação territorial e atlântica, expansionista e articuladora. Os meandros político-administrativos dessa tensão constituem-se nas questões abordadas a seguir.

\section{Entre o mar e o sertão: uma cidade sitiada}

\footnotetext{
15 BOXER, C. R. Salvador de Sá e a luta pelo Brasil e Angola, 1602-1686. São Paulo: Companhia Editora Nacional / Editora de Universidade de São Paulo, 1973.

${ }^{16}$ Cf. SAMPAIO, A C. J. de. Na Encruzilhada do Império. Hierarquias sociais e conjunturas econômicas no Rio de Janeiro (c. 1650-c. 1750). Rio de Janeiro: Arquivo Nacional, 2003.
} 
Em meados do século XVII, mais precisamente em 1646, o então governador Duarte Correa Vasqueanes escrevia ao rei sobre a conveniência de que todos os ministros seculares e eclesiásticos vivessem na parte alta da cidade. Propunha sua reconstrução no interior de muralhas para maior segurança dos moradores e da Fazenda Real diante de toda e qualquer invasão que as potências inimigas porventura intentassem. $^{17}$

A informação de Salvador de Sá sobre o projeto de Vasqueanes nos fornece um interessante relato do desenvolvimento espacial da urbe colonial desde os seus primórdios:

"A cidade do Rio de Janeiro teve seu princípio no monte de que trata o Governador na sua carta [morro do Castelo, que abrigava o Colégio dos Jesuítas, a Sé e o forte de São Sebastião], e depois pela maior comodidade do comércio se foi estendendo para a marinha aonde hoje está quase toda a povoação; porque até os moradores do outeiro se foram passando para baixo, deixando quase deserto aquele sítio que seus primeiros povoadores escolheram por mais forte, mais defensável e de melhores ares para a saúde." 18

Referendava o alvitre de Vasqueanes de que "no outeiro não só se conserve e renove a antiga povoação, mas que logo se trate de acrescentar moradores e casas nas quais se possam abrigar e viver os que em tempo de guerra ali se recolhem". ${ }^{19}$

Aquele projeto não foi, no entanto, adiante, uma vez que a vocação marítima e comercial da cidade não permitia que seus moradores abrissem mão de ocupar com suas casas, lojas e negócios as terras baixas da marinha. Da mesma forma, tornava-se indispensável que os funcionários da Coroa, ao menos aqueles ocupados com as atribuições administrativas e fazendárias, seguissem de perto homens e negócios, caso quisessem melhor exercer o seu ofício. Apenas as fortalezas, igrejas, conventos e

\footnotetext{
${ }^{17}$ AHU, RJ, Documentos Catalogados por Castro e Almeida (Catalogados C. A), doc. 543. Carta de 8 de julho de 1646.

${ }^{18}$ AHU, RJ, Catalogados C.A., doc. 545. Informação do vogal do Conselho Ultramarino Salvador Correa de Sá e Benevides, favorável à reedificação da cidade do Rio de Janeiro na parte alta do monte, de 10 de dezembro de 1646. O parecer do Conselho Ultramarino, após o exame das referidas carta e informação, era de que o Rei deveria mandar fortificar os outeiros do Rio de Janeiro a fim de que seus Ministros na colônia passassem a viver neles. Da mesma forma, deveria ordenar que as lojas de mercância, para a sua segurança, se metessem "da fortificação para dentro, e que de novo se não consinta fazer casas fora desta fortificação até ela estar bastantemente povoada". Cf. AHU, RJ, Catalogados C.A., doc. 542. Consulta de 12 de dezembro de 1646
} 
mosteiros permaneceram no alto dos outeiros, de onde podiam, sobranceiros, vigiar qualquer manifestação dos inimigos do rei e da fé.

À mesma época fora enviado de Portugal o engenheiro militar Miguel Lescolle. No Rio, se juntou a Felipe de Quitan, ao Capitão Francisco da Cruz - ambos provenientes da Bahia - e a outro perito em fortificações, que chegara de Angola em companhia de Salvador de Sá. Auxiliados por oficiais de guerra, percorreram o território urbano e as fortalezas, desenhando planos, elaborando relatórios e tecendo projetos das obras mais necessárias à sua defesa.

No primeiro relatório, datado de 20 de abril de 1647, constatava estar a cidade dividida em duas partes: a parte velha situada no alto do morro do Castelo, já àquela época quase despovoado. Consideravam ser importante fortificá-lo, "por ter grande senhoria sobre o plano da cidade nova". Do morro partia uma trincheira de terra e entulhos que o unia ao forte de Santiago, embora estivesse bastante arruinada. Defronte, mais para o interior, erguia-se outra colina, ocupada pelo Convento dos Capuchos, que também convinha fortificar.

$\mathrm{Na}$ outra ponta, a nordeste, erguiam-se mais dois outeiros, um bem próximo à povoação, em cujo cimo erguia-se o Mosteiro de São Bento. No segundo, não havia mais que a ermida de Nossa Senhora da Conceição e as ruínas de um pequeno reduto que um dia existira junto ao mar. Concordavam os engenheiros que aquelas duas colinas deveriam ser fortificadas, "assim por ter grande domínio sobre o plano da cidade, como também pela parte do mar", pois se localizavam sobre o principal ancoradouro dos navios, dominando a parte baixa, núcleo mercantil da urbe colonial. Concluíam, enfim, que convinha guarnecer o território urbano por todas as partes, "sem fazer comemoração do que de presente está feito", porque não era coisa de se vangloriar.

Num segundo relatório, datado de 22 de julho de 1649, sugeriam entrincheirar toda a extensão da marinha de pedra e cal, deixando apenas algumas serventias para o mar. A consulta do Conselho Ultramarino mostrou-se favorável à obra, recomendando que nela se trabalhasse "com todo o calor e diligência que pede a brevidade com que o inimigo pode cometer aquela praça, que pudera ser todas as horas, porque além de 
estarem tão vizinhos em Pernambuco, traz [sic] há muito tempo infestados aqueles mares desde a Bahia até aquela barra." 20

Não se sabe ao certo se tais projetos foram ou não executados na forma em que previam os engenheiros, sabe-se apenas que as sete plantas que desenharam nunca foram encontradas nos arquivos, quer no Brasil, quer em Portugal. ${ }^{21}$ De qualquer modo, o último quartel do século XVII foi de relativa paz entre as potências européias, o que pode sugerir um certo descuido da monarquia portuguesa, sempre carente de recursos e com tantos domínios a defender e sustentar, em relação à defesa e fortificação do Rio de Janeiro. Apenas em inícios da centúria seguinte - no contexto da Guerra de Sucessão espanhola, da necessidade de manutenção da Colônia do Sacramento e da descoberta do ouro nos sertões mineiros - a preocupação com a falta de defesa e segurança da cidade seria retomada.

Por volta de 1704, a idéia de cercar o território urbano por muralhas ganhara novo e redobrado vigor. Naquele ano, um ofício do governador D. Álvaro de Albuquerque alertava para a necessidade de edificação de uma trincheira que o circundasse inteiramente. Pela parte da marinha seu objetivo seria impedir que soldados e moradores lutassem a descoberto no caso de algum assédio estrangeiro. Serviria igualmente para evitar os descaminhos da Real Fazenda, facilitados pela existência de inúmeros boqueirões na costa. Pela parte do sertão propunha que se fizesse uma muralha "de faxina" com três baluartes ao longo da vala que marcava, àquela época, o limite da ocupação urbana. A vala, alargada e aprofundada, passaria então a servir de fosso aquático, como nos castelos medievais europeus. D. Álvaro parecia prever o que de fato iria acontecer alguns anos mais tarde, por ocasião da primeira invasão francesa (1710), quando os inimigos desembarcaram fora da barra e atacaram a cidade na altura da vala pela parte do continente. Porém, no momento em que propunha a construção da trincheira interior atribuía-lhe mais uma utilidade: o controle sobre a passagem de homens e de mercadorias para as Minas. De acordo com seu alvitre, "havendo portas

\footnotetext{
${ }^{20}$ AHU, RJ, Avulsos, Cx. 2, doc. 124-A. Relatórios de Miguel de Lescolle e Felipe de Quitan, e Consulta do Conselho Ultramarino, de 19 de dezembro de 1650. Os mesmos documentos acham-se transcritos em FERREZ, Gilberto. O Rio de Janeiro e a Defesa do seu Porto (1555-1800). Rio de Janeiro: Serviço de Documentação Geral da Marinha, 1972, pp. 156-179.

${ }^{21}$ Cf. FERREZ, op. cit., p. 26.
} 
em que se ponham guardas", seria mais fácil evitar o extravio dos direitos de Sua Majestade. $^{22}$

Apesar de tantos planos, plantas e projetos, a idéia de um muro que circundasse a cidade pelas bandas do sertão só viria a se concretizar a partir de 1713, obra concretizada pelo sentimento de medo vivenciado por administradores e colonos durante e após as invasões francesas de 1710 e 1711.

Em março de 1712, D. João V recomendava a Francisco de Távora, recémnomeado para assumir o governo do Rio de Janeiro que, com os engenheiros que levasse em sua companhia e com os demais que encontrasse na colônia, conferisse os pareceres dos seus antecessores sobre as fortificações que deveriam ser construídas para a melhor segurança da praça. Ordenava que começasse sem demora a trabalhar naquelas que se mostrassem indispensáveis para a sua imediata defesa. ${ }^{23}$ A 29 de outubro do mesmo ano uma nova carta régia anunciava o envio do engenheiro francês João Massé, "pessoa de tanta inteligência" que, de comum acordo com o governador, deveria executar o que fosse mais conveniente para tornar a cidade do Rio de Janeiro inexpugnável. $^{24}$

A 16 de agosto de 1713, Francisco de Távora respondia ao rei, esmiuçando a geografia das obras e fortificações que ele e Massé haviam iniciado. O ponto alto do projeto era "fechar a cidade fazendo um simples muro ao redor", não apenas para defendê-la caso fosse novamente, como em 1710, invadida por terra, mas para impedir a deserção dos soldados que tomavam o caminho das Minas. No dia 3 de dezembro, Távora remetia à metrópole as plantas das fortificações projetadas com o parecer dos engenheiros, dentre eles Massé. Afirmava que depois de construídas e postas "em sua última perfeição", a cidade do Rio de Janeiro se tornaria uma das "praças mais fortes que Vossa Majestade terá feito pelo mundo, que conduz para isso o bom sítio em que ela está assentada, e por esta causa não foi necessário fazer fortificações mais custosas". 25

\footnotetext{
${ }^{22}$ Arquivo Nacional do Rio de Janeiro (ANRJ), Códice 77, vol. 14, fls. 325v-328. Carta de 24 de maio de 1704.

${ }^{23}$ ANRJ, Cód. 952, vol. 18, fl. 195. Carta régia de 13 de março de 1712.

${ }^{24}$ ANRJ, Cód. 952, vol. 18, p. 253. Carta régia de 29 de outubro de 1712. Sobre Massé, ver FERREZ, $O$ Rio de Janeiro..., op. cit.; e, do mesmo autor, "João Massé e sua Planta do Rio de Janeiro de 1713" in Revista do Instituto Histórico e Geográfico Brasileiro (RIHGB), vol. 242, Rio de Janeiro, 1959.

${ }^{25}$ AHU, Cat. C. A., doc. 3.307. Carta de 3 de dezembro de 1713.
} 
Constituiu-se a muralha de Massé numa das obras de engenharia militar mais polêmicas da época, tanto para os seus contemporâneos quanto para a historiografia sobre o Rio de Janeiro setecentista. ${ }^{26}$ Uma acirrada disputa em torno do dito muro avançaria pelas décadas seguintes, dividindo os oficiais da Câmara de um lado, e os funcionários régios e militares, de outro. Em finais dos anos de 1720, o Senado do Rio de Janeiro solicitava ao rei que lhe permitisse aforar os chãos existentes "fora da inútil muralha que aqui se principiou". Afirmava serem os foros e laudêmios dos terrenos urbanos "o mais certo, ainda que limitado patrimônio desta Câmara". E dizia não haver no diminuto território da cidade, comprimido entre a marinha e a muralha, mais espaço "onde se fabriquem casas", não possuindo, em conseqüência disso, "outros chãos para se poder estender". ${ }^{27}$

O governador - que na época era Luís Vahia Monteiro - impedia que se aforassem os chãos ou que se construíssem casas no chamado Campo da Cidade, que se estendia para além da muralha. Solicitado a dar seu parecer sobre o requerimento do Senado da Câmara, Monteiro afirmava que apesar de o muro se encontrar "em meia obra", e muito particularmente lhe parecer inútil por ficar condenado pelo monte de Santo Antônio, exterior a ele, não achava conveniente deixá-lo "inutilizar mais com a fábrica de novos edifícios da parte da campanha”. Estes só poderiam ser construídos caso se demolisse a muralha, o que levaria à "total condenação das fortificações". 28

A inutilidade do muro era admitida por todos. Em 1735, o governador interino, Brigadeiro José da Silva Pais, remetia a Lisboa algumas plantas que havia feito das fortificações que considerava indispensáveis à segurança do Rio de Janeiro. Considerava que o modo mais seguro de defender a praça seria "cobrir a cidade e meter debaixo de uma muralha os seus moradores". Aproveitaria o muro de Massé, embora o considerasse de "pouca suposição". Nele construiria uma série de baluartes, transformando aquilo que até então não passara de um "muro de quinta", numa verdadeira muralha digna do porte e da importância da cidade. Além disso, pretendia ligar os montes da Conceição e de São Bento por uma trincheira, fechando inteiramente o território urbano. No futuro poderia levantar outro muro na marinha, "donde se lhe pode fazer um belo cais, de modo que não só fique defendida, senão ainda com formosura". Para tanto solicitava o envio de engenheiros da metrópole, que fizessem

\footnotetext{
${ }^{26}$ Cf. CAVALCANTE, Nireu. O Rio de Janeiro Setecentista. Rio de Janeiro: Jorge Zahar Editor, 2004.

${ }^{27}$ AHU, RJ, Avulsos, Cx. 20, docs. 19 e 72. Cartas de 9 de agosto de 1727 e de 21 de agosto de 1728.

${ }^{28}$ AHU, RJ, Avulsos, Cx. 20, doc. 19. Carta de 7 de julho de 1728.
} 
riscos e executassem os seus "pensamentos", coisa que já não alcançava devido à fraqueza de sua vista e ao trêmulo de suas mãos. ${ }^{29}$

Solicitado a dar o seu parecer, o Engenheiro Mor do Reino, Manuel de Azevedo Fortes, afirmava que os riscos e desenhos que examinara eram muito apropriados, não havendo "cousa que não seja preciso executar-se", tanto para a defesa da cidade por terra, quanto por mar. ${ }^{30}$

Não há notícia de que Silva Pais tenha levantado a muralha, embora a polêmica acerca do enclausuramento da cidade tenha mobilizado autoridades na colônia, conselheiros na metrópole e engenheiros especializados nos dois lados do Atlântico. Somente na década de 1750 as razões militares que pesavam nos argumentos dos governantes tiveram que ceder ao irreversível crescimento físico e populacional da cidade e à sua indiscutível vocação de articulação do território circundante. ${ }^{31}$

Na segunda metade do século XVIII, sobretudo após a transferência da sede do vice-reinado - período marcado pela delicada situação internacional que se configurou entre as potências européias após a Guerra dos Sete Anos (1756-1763) ${ }^{32}$-, a política metropolitana e o cuidado dos governantes em relação à defesa e segurança da então cidade-capital da colônia sofreram um ponto de inflexão. E esta inflexão articulará mais intimamente cidade e território, reafirmando sua capitalidade. ${ }^{33}$

\section{Defesa e território na afirmação da capitalidade}

A 16 de abril de 1761, D. José I, rei de Portugal, escrevia a Gomes Freire de Andrade, governador do Rio de Janeiro, ordenando-lhe que se transferisse à cidade de

\footnotetext{
${ }^{29}$ AHU, RJ, Cat. C.A., doc. 8.620. Carta de 3 de junho de 1735.

${ }^{30}$ AHU, RJ, Cat. C.A., doc. 8.622. Carta de Estremoz, datada de 10 de outubro de 1735.

${ }^{31}$ Em finais dos anos de 1750, o jesuíta Gabriel Malagrida solicitou ao governador interino José Antônio Freire de Andrade que pudesse utilizar o material do muro de Massé para a construção de um seminário nas proximidades da cidade. A 22 de abril de 1757, Andrade informava ao monarca haver-lhe concedido permissão para tal fim, já que também utilizava o que sobrara de sua demolição para as mais obras que fazia às custas da Fazenda Real. Cf. AHU, RJ, Avulsos, Cx. 60, doc. 58. Carta de 22 de abril de 1957.

${ }^{32}$ Cf. BICALHO, Maria Fernanda. A Cidade e o Império. O Rio de Janeiro no século XVIII. Rio de Janeiro: Civilização Brasileira, 2003, cap. 3.

${ }^{33}$ Não obstante, o ideal de cercar a cidade por muralhas sobreviveria, sendo reiterado na "pena", nos "riscos" e nas "plantas" de novos engenheiros militares - Francisco João Roscio, Jacques Funck e José Custódio de Sá e Faria (1769) - plenamente capacitados para lidar com as futuras imposições requeridas pela segurança e defesa da colônia diante dos novos desafios da engenharia de guerra européia e ultramarina.
} 
São Salvador da Bahia de Todos os Santos e tomasse posse do governo do Estado do Brasil. Em resposta, o então Conde de Bobadela argumentava que, devido ao fato de o novo governador nomeado para as Minas não haver ainda assumido o seu posto, e por considerar que as negociações com os espanhóis no sul da América portuguesa, em decorrência do Tratado de Madrid, demandassem administrador que residisse nas capitanias centrais ${ }^{34}$, julgava que abandonar o governo do Rio de Janeiro, "sem cabeça" incorreria em graves riscos. Afirmava ser aquela cidade "o manancial de que pende e se fortifica a conservação do Reino e das Conquistas", o que lhe fazia temer que "rota a âncora,[poderia] padecer o todo". Alegava ser o Rio de Janeiro o maior

"Empório do Brasil, pois tem este porto as circunstâncias de uma posição e defesa fortíssima e de uma barra incomparável. As principais forças militares que há no Brasil nele se acham; aqui entram, saem, e se manejam milhões [...] e a parte mais própria para dar socorros ao Norte ou ao Sul é sem questão este porto".

Defendia representar a cidade "a mais importante Jóia deste grande Tesouro. Aqui correm e correrão ao diante os mais importantes negócios, tanto da Coroa, como dos Vassalos; e assim se deve contar como antemural destas Províncias, de onde se podem socorrer e animar as outras". 35

Gomes Freire permaneceu à frente do governo do Rio por mais dois anos, até a sua morte em janeiro de 1763. Quatro meses depois, a 11 de maio, uma nova carta régia nomeava o Conde da Cunha Vice-Rei do Estado do Brasil, ordenando-lhe que passasse a residir na cidade do Rio de Janeiro. A 21 de dezembro, o Conde escrevia a D. José I, comunicando ter tomado posse do governo. ${ }^{36}$

A carência de documentação sobre as razões que motivaram a Coroa portuguesa a transferir a sede do vice-reinado de Salvador para o Rio de Janeiro leva-nos a enunciar algumas hipóteses, formuladas a partir da leitura da correspondência e da análise das políticas metropolitanas implementadas a partir da segunda metade do século XVIII.

\footnotetext{
${ }^{34}$ Gomes Freire acumulava os governos das capitanias do Rio de Janeiro e de Minas Gerais, e desempenhava o papel de plenipotenciário (embaixador) português nas negociações decorrentes do Tratado de Madri.

${ }^{35}$ Arquivo Histórico Ultramarino (AHU), Rio de Janeiro (RJ), Documentos Avulsos, Cx. 70, doc. 40. Ofício do Conde de Bobadela para o Conde de Oeiras, expondo os motivos que o impediam de cumprir a ordem régia relativa à sua transferência para a Bahia. Rio, 12 de abril de 1762.
} 
A década de 1760 presenciou o envio de experientes oficiais, engenheiros e tropas portuguesas para o Rio de Janeiro, como parte de uma política de unificação das forças militares do Reino e do ultramar, no bojo das reformas empreendidas pelo Conde de Lippe. ${ }^{37}$ As instruções dos ministros lisboetas dirigidas aos governadores das diversas capitanias insistiam que "as tropas deste Reino giram com as desse Estado; $e$ que todas elas constituem um só e único Exército debaixo das mesmas regras e da mesma idêntica disciplina, sem diferença alguma". ${ }^{38}$ Os ofícios enviados aos vice-reis advertiam-nos sobre o cuidado que deveriam ter em conservar as tropas, guarnecer a cidade, fortificar os portos e as marinhas e povoar os territórios incultos e sertões. Os esforços nesse sentido concentravam-se no Rio de Janeiro, de onde deveriam abranger as demais capitanias e partes da América portuguesa.

Reafirmava-se, assim, a interdependência das regiões coloniais nas questões relacionadas à defesa. ${ }^{39}$ De acordo com a Instrução Militar para uso do governador de São Paulo, de 1775,

"todas as Colônias portuguesas são de Sua Majestade e todos os que as governam são Vassalos seus: e nesta inteligência tanta obrigação tem o Rio de Janeiro de socorrer a qualquer das capitanias do Brasil, como cada uma delas de se socorrerem mutuamente umas às outras e ao mesmo Rio de Janeiro, logo que qualquer das ditas capitanias for atacada ou ameaçada de o ser: sendo certo que nesta recíproca união de poder consiste essencialmente a maior força de um Estado; e na falta dela, toda a fraqueza dele

Embora no que dizia respeito à segurança do território colonial, e mais especificamente da cidade do Rio de Janeiro, a correspondência oficial insistisse no reparo e na construção das fortalezas, quartéis e armazéns; no envio de militares, engenheiros, tropas e munições, e na organização - com os "naturais do país" - de

\footnotetext{
${ }^{36}$ AHU, RJ, Avulsos, Cx. 76, doc. 43. Ofício do Conde da Cunha, de 21 de dezembro de 1763.

${ }^{37}$ Cf. COSTA, Fernando D. "Guerra no tempo de Lippe e de Pombal" in BARATA, M. T \& TEIXEIRA, N. S. (dir.). Nova História Militar de Portugal. Lisboa: Círculo de Leitores, 2004, pp. 331-350.

38 "Relação das Instruções..." in RIHGB, vol. XXXV: 1, 1872, pp. 227-326.

${ }^{39}$ Essa interdependência vem sendo incentivada - e experimentada - desde o século XVII. Exemplo da sua eficácia num espaço aterritorial consistiu na reconquista de Angola aos holandeses pelos lusofluminenses, capitaneados por Salvador de Sá e Benevides. Cf. os já citados livros de BOXER e de ALENCASTRO.

${ }^{40}$ Instrução militar para uso do governador de São Paulo, de 24 de junho de 1775, apud MENDONÇA, Marcos Carneiro de. "O Pensamento da Metrópole em relação ao Brasil", RIHGB, Vol. 225, abril-junho de 1962, p. 194.
} 
Corpos Auxiliares e Milícias, as dimensões da defesa do patrimônio imperial ultrapassavam em muito o fortalecimento do aparato defensivo, técnico e militar da capital. Voltavam-se, prioritariamente, para a fundação de novas vilas, sua articulação com a cidade do Rio de Janeiro e com o vasto território adjacente. Em carta ao Conde de Oeiras, datada de sete de abril de 1767, o vice-rei Conde da Cunha afirmava:

"pelo que pertence à segurança da Capitania, entendo que fundando-se novas vilas nas margens marítimas desta costa que estão próximas a esta Cidade, assim ao norte como ao sul dela, [...] estes novos estabelecimentos fixarão de todo as portas da mesma Capitania, e a farão também muito florescente por ficarem tão próximas da sua Capital. Porém, Senhor, se por este facilíssimo método se não guarnecerem aquelas praias que têm bons e cômodos desembarcadouros, inúteis ficam sendo tantas fortalezas que neste porto e sua barra se têm fabricado, com tanta despesa assim na sua construção e petrechos, como na manutenção das suas guarnições." 41

Curioso paradoxo! Se a preocupação dos governantes insistia na necessidade de se fixarem "as portas", não mais da cidade, e sim da capitania, as chaves para tanto não se restringiam mais à edificação de trincheiras, fossos e muralhas, mas numa política de fundação de vilas. Duas semanas mais tarde, escrevendo ao Secretário de Estado Francisco Xavier de Mendonça Furtado, o vice-rei reafirmaria que,

"em muitas partes desta Costa, assim ao sul como ao norte desta barra, há algumas praias de cômodo jazido para lanchas e de facilíssimo desembarque; esta falta de segurança não se remedia com fortalezas, porque seriam necessárias tantas, que não caberia no tempo de muitos anos o construí-las, nem na possibilidade e rendimento da Capitania o provê-las de defensores e de munições competentes; pelo que só vilas populosas, fundadas nos sítios mais importantes e mais próximos às ditas praias, poderão dificultar e embaraçar qualquer improviso ataque."42

\footnotetext{
${ }^{41}$ AHU, RJ, Avulsos, Cx. 88, doc. 6. Ofício do Conde da Cunha ao Conde de Oeiras em que propõe remediar o estado de pobreza dos habitantes da Capitania aliado à segurança da mesma. RJ, 7 de Abril de 1767 (grifos meus).

${ }^{42}$ AHU, RJ, Avulsos, Cx. 88, doc. 15. Ofício do Conde da Cunha. RJ, 21 de abril de 1767.
} 
No mesmo ofício o Conde da Cunha argumentava que em vez de transplantar casais de gente das ilhas para povoar o Brasil - o que era dificultoso e gerava grande despesa -, o rei deveria prover os meios com que se pudessem fazer casas naquelas povoações, "porque toda a enorme populaça desta Capitania não tem nada de seu, tudo vive na maior miséria, e toda necessita da clemência e generosidade do seu Monarca". 43

Não foi a primeira vez que a política de defesa do território colonial era pensada levando em conta, para além da estrutura das fortificações, uma estratégia de fundação de vilas e fixação territorial da população. Em 1751, no calor das diligências em torno do Tratado de Madri - e no que diz respeito às fronteiras territoriais dos domínios de Portugal e Espanha - Sebastião José de Carvalho e Mello, futuro Marquês de Pombal, remetia a Gomes Freire uma "carta secretíssima", na qual afirmava:

"e como a força e a riqueza de todos os países consiste principalmente no número e multiplicação da gente que o habita, este número e multiplicação da gente se faz mais indispensável agora na raia do Brasil para a sua defesa, em razão do muito que tem propagado os Espanhóis nas fronteiras deste vasto continente". ${ }^{44}$

E como a grande quantidade de gente que se fazia necessária para povoar, guarnecer e sustentar uma "tão desmedida fronteira" não podia humanamente sair do Reino e das ilhas atlânticas, propunha que Gomes Freire estendesse aos índios Tapes que quisessem se transferir para o território luso, os privilégios de que gozavam os demais vassalos do Rei de Portugal.

Em suas instruções, de 1765, ao Morgado de Mateus, quando este assumiu o governo de São Paulo, o então Conde de Oeiras enumerava os três pontos que deveriam nortear sua administração: "o primeiro, garantir a fronteira, o segundo, povoar de modo que elas possam se defender, terceiro, fazer uso proveitoso das minas e riquezas

\footnotetext{
${ }^{43}$ Idem.

${ }^{44}$ AHU, RJ, Cat. C. A., doc. 15.192. Primeira carta secretíssima de Sebastião José de Carvalho e Mello, para Gomes Freire de Andrade. Lisboa, 21 de setembro de 1751.
} 
que possam ser descobertas nesse vasto continente". ${ }^{45}$ A mesma estratégia seria incentivada em todo a América portuguesa. Segundo Maria Helena Flexor,

“Uma análise histórica do período mostra a vontade do governo luso em povoar efetivamente o vasto território do seu domínio, através de uma política urbanizadora, especialmente decorrente da política geral do marquês de Pombal, de D. José I e dos tratados de limites do período. Começaram por libertar os índios e incentivar os casamentos de portugueses e índias, expulsar os jesuítas em 1759, mudar a capital do vice-reinado de Salvador para o Rio de Janeiro em 1763, depois da criação de uma Relação na cidade, fazer retornar à Coroa a posse de várias capitanias". ${ }^{46}$

A autora relaciona uma série de cartas régias que ordenavam a fundação de vilas nas aldeias indígenas de Porto Seguro e nas capitanias de São Paulo, Ceará e Maranhão. Não há que se esquecer da política urbanizadora empreendida durante o ministério pombalino, tanto na Amazônia, quanto em Mato Grosso. ${ }^{47}$

No que diz respeito especificamente ao Rio de Janeiro, a política de povoamento e fundação de vilas se impôs e se aprofundou durante toda a segunda metade do século XVIII, perpassando as instruções dirigidas ao Marquês de Lavradio, ${ }^{48}$ o seu relatório ao entregar o governo a Luís de Vasconcelos e Sousa, ${ }^{49}$ e as instruções dadas a este vice-rei pelo Secretário Martinho de Mello e Castro, em 1779. De acordo com estas últimas,

“a conservação das tropas na América, particularmente no Rio de Janeiro, é tão indispensavalmente necessária, como é demonstrativamente certo, que sem Brasil, Portugal é uma insignificante potência; e que o Brasil sem forças, é um preciosíssimo tesouro abandonado a quem o quiser ocupar."

\footnotetext{
45 Apud MAXWELL, Kenneth. A Devassa da Devassa. A Inconfidência Mineira: Brasil e Portugal, 1750-1808. Rio de Janeiro: Paz e Terra, 1978, p. 65.

${ }^{46}$ FLEXOR, M. H. "Núcleos urbanos planeados do século XVIII e a estratégia de civilização dos índios do Brasil”. In: SILVA, M. B. Nizza da. Cultura Portuguesa na Terra de Santa Cruz. Lisboa: Editorial Estampa, 1995, p. 79.

${ }^{47}$ Cf ARAÚJO, Renata M de. As Cidades da Amazônia no século XVIII. Belém, Macapá e Mazagão, Porto: FAUP, 1998, e, da mesma autora, A urbanização do Mato Grosso no século XVIII, op. cit.

${ }^{48}$ Cf. AHU, Códice 567.

${ }^{49}$ Cf. Revista Trimensal de História e Geographia, ou Jornal do IHGB, n 16, janeiro de 1843, p. 409 e segs.
} 
Por ser cabeça do Estado do Brasil e centro de articulação de fronteiras, territórios, redes de interesses e negócios no Atlântico sul, cabia à cidade do Rio de Janeiro a defesa do patrimônio, tanto régio, quanto de seus vassalos ultramarinos. Não custa lembrar as palavras de D. Luiz Antônio de Souza, reproduzidas no início deste artigo. A seu ver o Rio de Janeiro era a "chave deste Brasil", "uma das pedras fundamentais em que se afirma a [...] Monarquia, e em que [se] segura uma parte muito principal das suas forças e riquezas". 51

Nesse sentido, a noção e a experiência de capitalidade relacionadas ao Rio de Janeiro na segunda metade do século XVIII eram condizentes com seu papel de articulação política e econômica, assim como de defesa do território central e meridional da América, além de ser o principal porto do Atlântico sul. Esse papel se reafirma nos últimos anos daquela centúria, até que, em 1808, num extraordinário jogo de inversão, a cidade se metamorfosearia em Corte e capital da monarquia e do império português, redimensionando os elementos e o significado de sua capitalidade.

\footnotetext{
50 "Instruções de Martinho de Mello e Castro a Luís de Vasconcellos e Souza, de 27 de janeiro de 1779". RIHGB, T. XXV, 1862, p. 479-483.

${ }^{51}$ AHU, RJ, Avulsos, Cx. 80, doc. 22. Carta de D. Luiz António de Souza ao Conde de Oeiras. Rio de Janeiro, 26 de junho de 1765.
} 